\title{
Knowledge, Attitude, Fear, and Practice towards Coronavirus Disease-2019 Preventive Measures among Iranian Dentists
}

\author{
Isa Mohammadi Zeidi1,* and Banafsheh Mohammadi Zeidi ${ }^{2}$ \\ 1 Ph.D, Associate Professor, Social Determinants of Health Research Center, Research Institute for Prevention of Non-Communicable Diseases, Qazvin University \\ of Medical Sciences, Qazvin, Iran \\ ${ }^{2}$ Ph.D, Assistant Professor, Nursing and Midwifery Department, Tonekabon Branch, Azad University of Medical Sciences, Mazandaran, Iran
}

* Corresponding author: Isa Mohammadi Zeidi, Social Determinants of Health Research Center, Research Institute for Prevention of NonCommunicable Diseases, Qazvin University of Medical Sciences, Qazvin, Iran. Tel:+989124146500; Email: easamohammadizeidi@gmail.com

Received 2021 February 11; Revised 2021 June 24; Accepted 2021 June 29.

\begin{abstract}
Background: Dentists are more at risk of respiratory infectious diseases, compared to other Health Care Workers (HCWs).

Objectives: This study aimed to determine the relationship of knowledge, attitude, and fear with Coronavirus Disease-2019 (COVID-19) preventive measures amongst Iranian dentists.

Methods: This cross-sectional study was conducted in the northern provinces of Iran. In total, 340 dentists were selected using a multistage sampling method, and they were requested to complete the data collection tools, such as demographic characteristics form, knowledge scale, fear scale, attitude scale, and COVID-19 preventive measures scale. The obtained data were then analyzed by independent t-test, chi-square test, one-way ANOVA, correlation coefficient, and stepwise regression.

Results: Dentists' knowledge about issues, such as incubation period, laboratory test, virus survival time on surfaces, and method disinfection was weak. Nearly, $60 \%$ of the dentists had a favorable attitude towards the prevention of COVID-19, while their belief was not good on issues, such as adequacy of routine protocols, vulnerability towards COVID-19, suppressed immune system, patient's responsibility, and stigma. Moreover, $82.1 \%$ of dentists were fearful of being infected by patients, providing treatment to the suspected ones, the possibility of transmitting the infection to family members, post-infection quarantine, and treatment costs. Additionally, the total score of practice toward COVID-19 preventive measures in dentists was relatively high $(21.88 \pm 3.8)$, whereas their practice in criteria, such as presenting a special disinfectant solution or mask for patients, disinfecting surfaces, air conditioning, and examining patients' symptoms was not satisfactory. Regression analysis demonstrated that job history, knowledge, attitude, and fear were significant predictors of dentists' practice describing $62.7 \%$ of the variance in practice towards COVID-19 preventive measures.

Conclusion: The findings revealed that dentists had a comparatively good level of knowledge, attitude, and practice towards COVID-19 preventive measures. The current study suggests that dentists' anxiety, fear, and attitude could be remarkably reduced through providing adequate Personal Protective Equipment and subsequently enhancing preventive practice, raising awareness via online training regarding new guidelines, and presenting real-time statistics on the number of HCWS infected with COVID-19.
\end{abstract}

Keywords: Attitude, COVID-19, Dentist, Fear, Knowledge, Preventive measures

\section{Background}

The outbreak of the new coronavirus disease 2019 (COVID-19), an acute respiratory disease, has affected many aspects of life as one of the major public health problems that threaten the lives of thousands of people around the world (1). Although the World Health Organization (WHO) considers COVID-19 a controllable pandemic, its low pathogenicity and high transmissibility as two unique features of this virus distinguish it from other members of the coronavirus family, such as Severe Acute Respiratory Syndrome (SARS) and Middle East Respiratory Syndrome (MERS) (2). COVID-19 is likely to cause severe acute respiratory infection amongst infected people, which is usually transmitted from person to person through hands, saliva, nasal drops, and superficial contact (3). The average incubation period of COVID-19 is between 4 and 14 days and an infected person habitually complaining of upper respiratory tract infection, high fever, dry cough, and dyspnea (4).
No vaccine is currently available for preventing COVID-19, and patients should rely on supportive therapies, such as taking vitamins A, C, and D, as well as chloroquine phosphate (5). In addition, regarding the vital role of the immune system, the elderly and patients with chronic debilitating diseases are at a higher risk of infection, compared to healthy young people (6).

Due to the rapid spread of COVID-19, many countries have suspended educational activities, meetings, sports activities, events, public transportation, and financial institutions' business to control the spread of infection. However, health care facilities, as a vital necessity for any community, are seldom shut down under such epidemic conditions. Accordingly, healthcare workers (HCWs) could be regarded as one of the most vulnerable groups with the highest risk towards respiratory and infectious diseases, such as COVID-19 (7). COVID-19 imposes serious occupational health risks on HCWs due to frequent exposure to infected individuals. A review of mortality and morbidity associated with many 
infectious diseases, such as SARS and Ebola has displayed that HCWs are at the forefront of the danger of infection and death. In addition, evidence has highlighted the high rate of infection and mortality from COVID-19 in nurses, physicians, and other HCWs since the beginning of the outbreak (3). In this regard, dentists, mainly due to the performance of specialized dental duties, such as being in close contact with patients, as well as excessive exposure to aerosols and droplets coming out of the patients' oral cavity, are always more at risk of respiratory and infectious diseases than other HCWs (8). Moreover, according to occupations' classification -based on the degree of exposure to illness, physical proximity to patients during care providing, and the possibility of remote work- it was found that dentistry, hospital care, veterinary, general physician, and home nursing are amongst the occupations with the highest risk in descending order (9).

Positive cases of COVID-19 can be asymptomatic for a long time while they are able to transmit the disease to health professionals easily, especially dentists (10). To date, no accurate statistics have been reported on the prevalence of COVID-19 among the general population, medical staff, and dentists in Iran. Nevertheless, cross-sectional studies highlighted the worrying conditions associated with the prevalence of COVID-19 among Iranian HCWs. Considering the study of Sarkarat et al. (2020), the prevalence of COVID-19 was reported to be $2.2 \%$ in a sample consisting of 1,110 dentists, with the highest and lowest incidence rates being in ceramists (50\%) and dental students (3.19\%), respectively (11).

The American Dental Association (ADA) has announced a set of important steps in addition to the standard precautions that dentists have to take to prevent COVID-19. Examples of these measures include assessing the patient's risk level through a special questionnaire, reviewing patients' recent travel history, evaluating the symptoms of upper respiratory tract infection, recording patients' body temperature, performing regularly hand hygiene before starting any treatment process, washing mouth with 1\% hydrogen peroxide, using a rubber dam and high volume suction, orderly cleaning, and disinfecting of frequent contact areas (e.g., door handles, chairs and toilets), regular and correct utilization of appropriate personal protective equipment (PPE), and proper waste management $(8,12)$.

A great number of dental clinics worldwide have returned to normal just a few months after the outbreak of COVID-19, mainly due to a variety of ethical, professional, and economic reasons. In such a situation, controlling the COVID-19 pandemic via stopping the transmission of the virus requires several strategies, such as applying health restrictions, tracking infected and suspected cases, maintaining social distance, and quarantining individuals at risk of infection (13). Moreover, elevating the level of awareness, as well as changing the attitude of different groups, especially high-risk jobs, such as dentistry, could be a highly effective strategy in controlling the disease (14). Given the results of Geldsetzer (2020), successful management and minimization of COVID-19 mortality demand altering behaviors that are influenced by knowledge and beliefs of high-risk groups (15).

With respect to the infection of several thousands of HCWs, prevention of the intra-hospital spreading of this contagious disease is now a high priority. Moreover, the lack of sufficient knowledge and misunderstanding in HCWs has led to delayed diagnosis, disease spreading, and poor infection control function (16). In this regard, the implementation of preventive behaviors by dentists would be one of the most effective ways, which could not only prevent the dentists and their families from getting infected but also control the prevalence of COVID-19 in the community (17). Since the onset of the current pandemic, WHO has published and launched several guidelines, online courses, and training sessions to enhance awareness and preparedness of HCWs regarding the prevention and control of COVID-19 (18). Therefore, appraising awareness, attitude, and practice of HCWs, such as dentists, can be a good procedure to evaluate existing programs, as well as expand efficient strategies for changing behavior in society.

The nature of treatments in dentistry creates the possibility of cross-infection between the patient and the dentist. Therefore, the principles of infection control must be carefully implemented to increase the level of immunity for patients and dentists $(3,8,17)$. Currently, standard protective measures are not adequate to avert the spread of COVID-19. Accordingly, effective adherence to preventive protocols is indispensable, and dentists should be encouraged to cling strictly and consistently to such protocols in addition to personal protection standards.

Despite the emphasis on dentists' vulnerability as well as the importance of following standard protocols and preventative practice, numerous dentists do not execute the recommended guidelines (19). The results of a study conducted by Ahmed et al. (2020) indicated that $90 \%$ of dentists were not aware of changes in treatment protocols, with $40 \%$ not implementing new treatment protocols (20).

The impact of fear as a powerful factor on health care should not be overlooked. Fear is a negative emotion that leads to the avoidance of certain stimuli based on perceived risk. In many situations, fear is an appropriate response that can reduce involvement in high-risk behaviors, or conversely, lead to greater adherence to relieving strategies, such as social distancing or handwashing (21). Fear can also be accompanied by maladaptive behaviors, such as either requesting complex laboratory tests, unnecessary medical care, or buying and hoarding 
expensive medical devices, including expensive PPE (22). The level of fear during the pandemic of COVID19 has been sharply risen due to extreme emergencies, poor information, and rumors on social media. More than $50 \%$ of the general population reported that the COVID-19 outbreak had moderate to severe psychological effects (23).

Moreover, the results of some studies indicated that despite the high level of awareness and practice, dentists around the world suffer from anxiety and fear due to the impact of COVID-19 on humanity $(20,24)$. In this regard, Consolo et al. (2020) revealed that 85\% of dentists are anxious to perform their professional duties during the COVID-19 pandemic, and according to a study performed by Ahmed et al. (2020), 87\% of the dentists, selected from 30 different countries, were afraid of developing COVID-19 $(20,25)$.

The fear and anxiety have resulted in the adjustment of treatment procedures in accordance with the recommended guidelines and the provision of medical services only for emergencies or the closure of dental clinics for an indefinite period of time (21). Therefore, it is crucial to evaluate the psychological profile of dentists to determine their psychological readiness to resume dental activities, along with adhering to health preventive protocols.

The results of previous studies indicated that insufficient knowledge and unfavorable attitude of HCWs regarding the degree of vulnerability, as well as the severity of the disease consequences (associating with the low level of fear and threats), could be reasons for non-compliance with preventive behaviors of SARS and COVID-19 (18, 20, 26, 27).

The reason for the failure of behavioral change interventions is attributed to the lack of adequate attention, as well as improper evaluation of psychosocial variables affecting the adoption of disease prevention behaviors (28). As a result, understanding the factors influencing the adoption of preventive behaviors in health care providers, such as the application of appropriate personal protective equipment, is a vital step in designing educational programs and behavior change interventions (29).

\section{Objectives}

This study aimed to determine the relationship of knowledge, attitude, fear, and practice with COVID-19 preventive measures among Iranian dentists.

\section{Methods}

The present cross-sectional study was conducted from April 4 to July 18, 2020, in the northern and central provinces of Iran.

\subsection{Participants and sampling process}

The study population included all dentists working in public and private sectors in five provinces of Tehran, Qazvin, Mazandaran, Gilan, and Golestan, Iran.

The sample size $(n=340)$ was determined on the basis of a study performed by Gambhir et al. (2020) (27), G*Power software, 95\% confidence interval, and a tolerable error value of 0.05 (d).

Regarding the significant difference in the total number of dentists working in each province, the number of dentists required for this study was determined according to the ratio of the total population of dentists in each province as follows: Tehran ( $n=113)$, Mazandaran $(n=75)$, Gilan $(n=66)$, Qazvin $(n=46)$, and Golestan $(n=40)$. The inclusion criteria were: 1) voluntary participation in research, 2) a general dentist or higher, 3) employment in public clinics or private offices, and 4) residency in one of the five provinces while conducting research. The dentists' selection to participate in the study was carried on using a table of random numbers. Subsequently, the research team contacted the selected ones by telephone and explained the investigation objectives to them. Phone numbers and e-mail addresses were received from all dentists who volunteered to partake in the study in order to explain how to participate in it.

\subsection{Data gathering process}

Questionnaires were provided to partakers both physically and via e-mail or WhatsApp Messenger, and all individuals were asked to reply to questions within 20 days. During this time, four reminders were sent to each participant through SMS, as well as WhatsApp to complete the questions. It should be noted that along with the questionnaires, two forms were provided to the participants, including written consent and a guide to answering the queries. After the mentioned time, the questionnaires were collected by trained experts in order to be reviewed in terms of answering all questions, not including the name and surname, as well as providing an educational package comprising an educational pamphlet, a CD with the subject of prevention of COVID-19, a pocket calendar, and a participation certificate (as prizes for engagement in the research).

All participants in the study were assured that their information would definitely be kept confidential by the research team, with the questionnaires being anonymous. Moreover, it was emphasized that their participation in the research was voluntary. The present study has been approved by the Ethics Committee of Qazvin University of Medical Sciences, Qazvin, Iran (IR.QUMS.REC.1399.190).

\subsection{Data collection instruments}

Data were collected using a set of selfadministrative questionnaires. The tools utilized in this research were as follows: 


\subsubsection{Demographic characteristics form}

It covers such information as age (year), gender, marital status, job experience (year), type of dental specialty, province (city), history of participation in the training course related to COVID-19 (yes/no), number of daily visits in the past month, decrease in the number of dental visits since the outbreak of COVID-19 (yes/no), self-assessment of information about COVID-19 (How do you rate your knowledge on COVID-19 in general? Excellent/good/average/poor), and source of information about COVID-19.

\subsubsection{COVID-19 Knowledge Scale}

It consists of 15 items aiming at assessing dentists' knowledge regarding disease-relevant details, such as virus type, common symptoms, methods of transmission, access to the vaccine, and various prevention measures. Participants were demanded to respond to the questions using "true-false" and "I don't know" options. Each true answer was given a score of one, with the false answers a score of zero. The sum of the answers was utilized to calculate the total score of knowledge, with the range of scores varying between 0 and 15. The final score of knowledge was classified into three levels of low (5-0), medium (6-10), and high (11-15). The items used in this scale were "COVID-19 is not transmissible from asymptomatic patients" and "all contaminated surfaces should be cleaned with a dilute disinfectant solution".

The validity and reliability of the knowledge scale have been well established in previous studies (26, 27). In the present study after the back translation process, the face and content validity of the knowledge scale was also confirmed by an expert panel consisting of a general dentist, an infectious disease specialist, a general physician, a psychologist, and a health education specialist. Content Validity Rate (CVR) and Content Validity Index (CVI) were obtained at 0.83 and 0.87 , respectively. Moreover, the knowledge scale was completed by a group of 15 dentists at two-week intervals, where the correlation coefficient of the answers in two stages showed good reliability of the scale $(r=0.92)$. The sample was randomly chosen from the main population, with their findings not being included in the results of the main study.

\subsubsection{COVID-19 Fear Questionnaire}

This scale was developed by Putrino et al. (2020) (26) and consists of eight items. Dentists were requested to respond to items using the "true-false" and "I don't know" options. Examples of items relevant to this questionnaire were as follows: "if a patient speaks to me at a very close distance, I get nervous" and "I'm afraid that I might pass the infection on to my family because of my dental work". The face and content validity of this questionnaire was approved by a panel of experts (CVR=0.75,
CVI=0.78). In addition, Cronbach's alpha coefficient $(\alpha=0.79)$ and retest coefficient $(r=0.82)$ confirmed the internal consistency and reliability of the questionnaire, respectively.

\subsubsection{The Attitude Scale}

It comprises of eight items, and the participants were asked to answer the items using a 5-point Likert scale from 1 (strongly disagree) to 5 (strongly agree). The scores ranged from 8 to 40 , and higher scores indicate a more favorable attitude towards COVID-19 preventive measures. Some items in this questionnaire include "Most patients who go to dental clinics are responsible people, and I am not worried about getting the disease through them" and "dentists are more likely to get COVID-19 than other HCWs". The psychometric properties of the scale have been confirmed in previous studies $(30,31)$. After the translation process in the current study, its face and content validity was approved by an expert panel. In addition, a sample of 15 dentists completed the questionnaire twice in two weeks intervals in which a correlation coefficient between the two-step answers was used to assess the reliability of the questions. Content validity, reliability, and internal consistency of the questions were confirmed by $\mathrm{CVI}=0.86, \mathrm{CVR}=0.81, \mathrm{r}=0.94$, and $\alpha=0.89$, respectively.

\subsubsection{COVID -19 preventive practice questionnaire}

Regarding previous studies, this questionnaire included items, such as regular disinfection of equipment and places, the use of a high volume suction and Rubber Dam isolation, requesting patients to rinse their mouth with an antibacterial mouthwash before treatment, and washing hands with antibacterial solution pre-post dental treatment $(30,32,33)$. Dentists were demanded to reply to 12 items of this questionnaire using "yes, no" and "I do not know" options.

Some related items were: "I always use personal protective equipment such as gloves, face shield, head cover, and masks" and "I accurately assess the symptoms of upper respiratory tract infection and patients' body temperature". The validity and reliability of this questionnaire have been proven in previous studies $(32,33)$. In this study, CVR and CVI ( 0.81 and 0.85 , respectively) confirmed the content validity, and Cronbach's alpha coefficient $(\alpha=0.90)$, as well as a test-retest coefficient $(\mathrm{r}=0.88)$ proved the internal consistency and reliability of the questionnaire, respectively.

\subsection{Statistical analysis}

The data were entered into SPSS software (version 25.0), and their normality distribution was assessed using the Kolmogorov-Smirnov test. Following that, they were subjected to the following analyses: Chisquare test (to examine the relationship between qualitative variables, such as gender and levels of 
knowledge), independent t-test (to compare the mean of a quantitative variable between two independent groups, such as the mean score of attitude between married and single dentists), ANOVA (to compare the mean of quantitative variables between either two independent groups or more, such as the mean score of fear between dentists based on job experience less than 2 years, 25 years, and more than 5 years), and Pearson correlation coefficient (to examine the relationship among quantitative variables, such as the mean score of knowledge, attitude, fear, and practice). In addition, stepwise regression analysis was used for identifying the factors affecting the preventive behaviors of COVID-19 in dentists. A p-value less than 0.05 was considered statistically significant.

\section{Results}

\subsection{Demographic characteristics of participants}

The mean age of dentists participating in this study was obtained at $37.54 \pm 11.5$ years (age range: $26-60$ years), and the mean of job experience was determined at $9.30 \pm 6.44$. Furthermore, the majority (53.23\%) of the participants were male, and $72.35 \%$ of them were general dentists. Approximately, $70 \%$ of the respondents had received no formal training about COVID-19, and only $30.29 \%$ of them used the protocols and instructions of the Ministry of Health as a source of information regarding COVID-19. The other demographic characteristics are provided in Table 1.

\subsection{Dentists' knowledge toward COVID -19}

Table 2 describes the dentists' responses to their knowledge regarding COVID-19. Of the 340 dentists, $81.63 \%$ of them answered the knowledge questions correctly and according to Table 2, $73.53 \%$ of the dentists had a high level of knowledge. In addition, $7.47 \%$ of the participants responded to the knowledge questions incorrectly with $6.76 \%$ having a low level of knowledge. Wrong answers were clearly reported in the questions related to the incubation period (18.82\%), laboratory test $(20.0 \%)$, virus survival time on surfaces (12.94\%), and methods of surface disinfection (11.47\%).

\subsection{Mean score of knowledge of dentists in terms of demographic variables}

The results of comparing the mean score of knowledge of dentists in terms of some demographic variables are given in Table 3 . According to the outcomes of one-way ANOVA, the mean score of knowledge in terms of job experience was significantly different amongst the participated dentists $(\mathrm{P}=0.001)$. In other words, the mean score of knowledge in dentists with job experience of more than 10 years was significantly superior to that of the others $(12.33 \pm 2.3, \mathrm{P}=0.001)$. Moreover, the mean score of knowledge of dentists who reported the Ministry of Health, WHO, and Centers for Disease Control and Prevention (CDC) as main sources to access information about COVID-19 prevention was significantly higher than that of others $(12.45 \pm 2.38$, $\mathrm{P}=0.001)$.

\subsection{Dentists' attitude toward COVID-19 preventive behaviors}

Table 4 tabulates the dentists' responses to

\begin{tabular}{|c|c|c|c|}
\hline Variables & Frequency (\%) & Variables & Frequency (\%) \\
\hline age (year) & & How much do you know about COVID-19? & \\
\hline Less than 30 & $75(22.06)$ & Excellent & $251(73.82)$ \\
\hline $31-45$ & $163(47.94)$ & Good & 53 (15.59) \\
\hline More than 45 & $102(30.0)$ & Medium & $25(7.35)$ \\
\hline Gender & & Weak & $11(3.24)$ \\
\hline Male & $181(53.23)$ & What is the number of daily visits? (case) & \\
\hline Female & 159 (46.77) & less than 5 & $31(9.12)$ \\
\hline Marital status & & 6-10 & $118(34.70)$ \\
\hline Married & $207(60.88)$ & $12-15$ & $121(35.59)$ \\
\hline Single & $106(31.18)$ & more than 15 & $70(20.59)$ \\
\hline Divorced & $27(7.94)$ & Have daily referrals decreased since the outbreak? & \\
\hline Job experience (year) & & Yes & $218(64.12)$ \\
\hline Less than 2 & $31(9.12)$ & No & $65(19.12)$ \\
\hline $2-5$ & $66(19.41)$ & No difference & $57(16.76)$ \\
\hline $5-10$ & $107(31.47)$ & Main source of information about COVID-19? & \\
\hline More than 10 & $136(40.0)$ & Ministry of Health, WHO, and CDC & $103(30.29)$ \\
\hline Dental specialty & & Mass media, such as television, radio, newspapers & $116(34.12)$ \\
\hline General dentist & $246(72.35)$ & Web, Whats App, and Instagram & $94(27.65)$ \\
\hline Orthodontic & $30(8.82)$ & Significant others as colleagues, family, and friends & $27(7.94)$ \\
\hline Surgery & $35(10.29)$ & Province & \\
\hline Children & $8(2.35)$ & Tehran & $113(33.24)$ \\
\hline Periodontology & $11(3.24)$ & Mazandaran & $75(22.06)$ \\
\hline COVID-19 formal training? & & Guilan & $66(19.41)$ \\
\hline Yes & $103(30.29)$ & Qazvin & $46(13.53)$ \\
\hline No & $237(69.71)$ & Golestan & $40(11.76)$ \\
\hline
\end{tabular}


Table 2. Dentists' knowledge toward COVID-19 (n=340)

\begin{tabular}{|c|c|c|c|}
\hline Items & $\begin{array}{c}\text { Yes } \\
\text { Frequency } \\
(\%)\end{array}$ & $\begin{array}{c}\text { NO } \\
\text { Frequency } \\
(\%)\end{array}$ & $\begin{array}{l}\text { Don't know } \\
\text { Frequency } \\
\text { (\%) }\end{array}$ \\
\hline The incubation period of COVID -19 is 1 to 21 days. & $248(72.94)$ & $64(18.82)$ & $28(8.24)$ \\
\hline $\begin{array}{l}\text { The main symptoms of COVID-19 include fever }>38^{\circ} \mathrm{C} \text {, cough, sore throat, runny } \\
\text { nose, and dyspnea. }\end{array}$ & $322(94.71)$ & $8(2.35)$ & $10(2.94)$ \\
\hline $\begin{array}{l}\text { Dentists must take strict personal protective measures and avoid or minimize } \\
\text { operations that can produce droplets or aerosols. }\end{array}$ & $313(92.06)$ & $13(3.82)$ & $14(4.12)$ \\
\hline COVID-19 can be prevented by prescribing the vaccine & $330(97.06$ & $4(1.18)$ & $6(1.76)$ \\
\hline All patients should gargle before treatment during the COVID-19 epidemic. & $302(88.82)$ & $16(4.71)$ & $22(6.47)$ \\
\hline rRT-PCR is an available laboratory test to detect COVID-19. & $245(72.06)$ & $68(20.0)$ & $27(7.94)$ \\
\hline $\begin{array}{l}\text { During the COVID- } 19 \text { epidemic, treatment is given if there is a pain in cases } \\
\text { undergoing orthodontic treatment in which the brackets and wires are } \\
\text { dislocated or broken }\end{array}$ & $309(90.88)$ & $14(4.12)$ & $17(5.0)$ \\
\hline COVID-19 is transmitted through direct contact with respiratory secretions. & $300(88.24)$ & $8(2.35)$ & $1(0.29)$ \\
\hline COVID-19 can remain on the surface for hours or even days. & $268(78.82)$ & $44(12.94)$ & $28(8.24)$ \\
\hline COVID-19 is not transmissible from asymptomatic patients. & $315(92.65)$ & $8(2.35)$ & $17(5.0)$ \\
\hline $\begin{array}{l}\text { The use of personal protective equipment (including masks, gloves, or face } \\
\text { shields) is recommended to protect the skin and mucous membranes from } \\
\text { potentially contaminated blood or secretions. }\end{array}$ & $322(94.71)$ & $12(3.53)$ & $6(1.76)$ \\
\hline $\begin{array}{l}\text { Hand hygiene is the most important measure to reduce the risk of transmission } \\
\text { of COVID-19 to patients }\end{array}$ & $293(86.18)$ & $35(10.29)$ & $12(3.53)$ \\
\hline $\begin{array}{l}\text { All infected surfaces of patients with COVID-19 infection should be cleaned with } \\
\text { dilute disinfectant solution (5\%) }\end{array}$ & $264(77.65)$ & $39(11.47)$ & $37(10.88)$ \\
\hline $\begin{array}{l}\text { Pneumonia, respiratory failure, and death from COVID-19 are more common in } \\
\text { the elderly and people with chronic diseases. }\end{array}$ & $305(89.71)$ & $20(5.88)$ & $15(4.41)$ \\
\hline $\begin{array}{l}\text { Keeping a safe distance from patients and avoiding eye, mouth, and nose contact } \\
\text { is effective in preventing COVID -19. }\end{array}$ & 311 (91.47) & $12(3.53)$ & $17(5.0)$ \\
\hline
\end{tabular}

Table 3.Comparison of mean \pm SD of dentists' knowledge score related to COVID-19 in terms of some demographic variables ( $\mathrm{n}=340$ )

\begin{tabular}{|c|c|c|c|}
\hline Variables & & Knowledge $\mathrm{M} \pm \mathrm{SD}$ & Significant Level \\
\hline \multirow{3}{*}{ Age (Year)* } & Less than 30 & $10.67 \pm 1.56$ & \multirow{3}{*}{0.390} \\
\hline & 31-45 & $10.14 \pm 1.65$ & \\
\hline & More than 45 & $10.43 \pm 2.14$ & \\
\hline \multirow{4}{*}{ Job experience (year) ${ }^{* *}$} & Less than 2 & $10.14 \pm 1.77$ & \multirow{4}{*}{0.001} \\
\hline & $2-5$ & $10.25 \pm 1.86$ & \\
\hline & 5-10 & $9.93 \pm 2.05$ & \\
\hline & More than 10 & $12.33 \pm 2.15$ & \\
\hline \multirow{2}{*}{ Training about COVID-19 $* *$} & Yes & $10.34 \pm 2.26$ & \multirow{2}{*}{0.713} \\
\hline & No & $10.52 \pm 1.94$ & \\
\hline \multirow{6}{*}{ Dental specialty** } & General dentist & $10.42 \pm 2.08$ & \multirow{6}{*}{0.713} \\
\hline & Orthodontic & $10.00 \pm 1.97$ & \\
\hline & Surgery & $10.28 \pm 1.72$ & \\
\hline & Pediatric & $10.94 \pm 2.00$ & \\
\hline & Periodontology & $11.13 \pm 2.17$ & \\
\hline & Others & $10.41 \pm 2.05$ & \\
\hline \multirow{4}{*}{ COVID-19 information source** } & $\begin{array}{l}\text { Ministry of Health, World Health Organization, and the } \\
\text { Centers for Disease Control and Prevention }\end{array}$ & $12.45 \pm 2.38$ & \multirow{4}{*}{0.001} \\
\hline & Mass media, such as television, radio, and newspapers & $9.52 \pm 1.95$ & \\
\hline & Web, WhatsApp, and Instagram & $10.50 \pm 2.35$ & \\
\hline & Significant others as colleagues, family, and friends & $10.39 \pm 2.13$ & \\
\hline
\end{tabular}

various items of the attitude scale. According to the results, $73.83 \%$ of the dentists agreed that they could prevent COVID-19 by following routine hygiene protocols with $32.94 \%$ believing that they were more susceptible to COVID-19, compared to other HCWs. Moreover, $26.76 \%$ of the dentists believed that they would not probably get infected with COVID-19 unless they had an underlying disease or a suppressed immune system. In addition, $73.23 \%$ of the dentists believed that their colleagues would blame them if they got COVID-19. In total, $23.79 \%$ of the dentists had an unfavorable attitude with $59.96 \%$ having a desirable attitude towards the prevention of COVID-19.

\subsection{Dentists' fears and anxieties on COVID-19}

Dentists' fears and anxieties on COVID-19 are presented in Table 5. Results revealed that $85.29 \%$ of the dentists were fearful of getting infected with COVID-19 via patients or colleagues. It was also found that the treatments of patients with suspected COVID-19 caused anxiety in $89.12 \%$ of dentists, and $72.94 \%$ of them decided to stop their dental activities until a reduction in the prevalence of COVID-19. Additionally, more than $74.41 \%$ of the participants reported that talking to patients at very close distances would make them nervous, with more than 93.53\% of the dentists being feared for transmitting the disease to their family through dental activity. 


\begin{tabular}{|c|c|c|c|c|c|}
\hline $\begin{array}{l}\text { Adherence to routine hygiene protocols is sufficient to } \\
\text { prevent COVID-19 in dentistry. }\end{array}$ & $\begin{array}{c}31 \\
(9.12)\end{array}$ & $\begin{array}{c}39 \\
(11.47)\end{array}$ & $\begin{array}{c}19 \\
(5.59)\end{array}$ & $\begin{array}{c}201 \\
(59.12)\end{array}$ & $\begin{array}{c}50 \\
(14.71)\end{array}$ \\
\hline Dentists are more likely to get COVID-19 than other HCWs. & $\begin{array}{c}29 \\
(8.53)\end{array}$ & $\begin{array}{c}137 \\
(40.29)\end{array}$ & $62(18.24)$ & $\begin{array}{c}106 \\
(31.18)\end{array}$ & $\begin{array}{c}6 \\
(1.76)\end{array}$ \\
\hline $\begin{array}{l}\text { If I do not have an underlying disease or a suppressed } \\
\text { immune system, I am less likely to get COVID }-19\end{array}$ & $213(62.65)$ & $\begin{array}{c}12 \\
(3.53)\end{array}$ & $\begin{array}{c}24 \\
(7.06)\end{array}$ & $\begin{array}{c}51 \\
(15.0)\end{array}$ & $40(11.76)$ \\
\hline $\begin{array}{l}\text { In the current situation, only patients with serious } \\
\text { conditions should be visited in the dental clinic. }\end{array}$ & $\begin{array}{c}6 \\
(1.76)\end{array}$ & $\begin{array}{c}10 \\
(2.94)\end{array}$ & $\begin{array}{c}14 \\
(4.12)\end{array}$ & 116 & $\begin{array}{c}194 \\
(57.06)\end{array}$ \\
\hline $\begin{array}{l}\text { Most people who go to dental clinics are responsible people, } \\
\text { and I am not worried about getting infected through them. }\end{array}$ & $\begin{array}{c}71 \\
(20.88)\end{array}$ & $\begin{array}{c}39 \\
(11.47)\end{array}$ & $69(20.29)$ & $\begin{array}{c}46 \\
(13.53)\end{array}$ & $115(33.82)$ \\
\hline $\begin{array}{l}\text { Due to my good physical condition, even if I get infected } \\
\text { with COVID-19, I will recover after a few days of rest. }\end{array}$ & $\begin{array}{c}171 \\
(50.29)\end{array}$ & $\begin{array}{c}99 \\
(29.12)\end{array}$ & $\begin{array}{c}19 \\
(5.59)\end{array}$ & $31(9.12)$ & $\begin{array}{c}20 \\
(5.88)\end{array}$ \\
\hline $\begin{array}{l}\text { If a dentist is infected with COVID-19, society will blame } \\
\text { him/her. }\end{array}$ & $\begin{array}{c}13 \\
(3.82)\end{array}$ & $\begin{array}{c}48 \\
(14.12)\end{array}$ & $\begin{array}{c}30 \\
(8.82)\end{array}$ & $83(24.41)$ & $\begin{array}{c}166 \\
(48.82)\end{array}$ \\
\hline COVID-19 is a severe and deadly infectious disease. & $\begin{array}{c}19 \\
(5.59)\end{array}$ & $\begin{array}{c}12 \\
(3.53)\end{array}$ & $\begin{array}{c}24 \\
(7.06)\end{array}$ & $\begin{array}{c}245 \\
(72.06)\end{array}$ & $\begin{array}{c}40 \\
(11.76)\end{array}$ \\
\hline
\end{tabular}

\begin{tabular}{|c|c|c|c|}
\hline Items & $\begin{array}{c}\text { Yes } \\
\text { N (\%) }\end{array}$ & $\begin{array}{c}\text { No } \\
\text { N (\%) }\end{array}$ & $\begin{array}{l}\text { I don't know } \\
\text { N (\%) }\end{array}$ \\
\hline I'm afraid of getting infected with COVID-19 through patients or colleagues. & $\begin{array}{c}290 \\
(85.29)\end{array}$ & $\begin{array}{c}43 \\
(12.65)\end{array}$ & $\begin{array}{c}7 \\
(2.06)\end{array}$ \\
\hline $\begin{array}{l}\text { I get anxious when I provide treatment to a patient who coughs or is } \\
\text { suspicious of getting infected with symptoms of COVID-19. }\end{array}$ & $\begin{array}{c}303 \\
(89.12)\end{array}$ & $\begin{array}{c}27 \\
(7.94)\end{array}$ & $\begin{array}{c}10 \\
(2.94)\end{array}$ \\
\hline $\begin{array}{l}\text { I want to close my office or reduce my working hours until the number of } \\
\text { patients with COVID-19 decreases. }\end{array}$ & $\begin{array}{c}248 \\
(72.94)\end{array}$ & $\begin{array}{l}79 \\
(23.24)\end{array}$ & $\begin{array}{c}13 \\
(3.82)\end{array}$ \\
\hline I get nervous if a patient talks to me at very close distances. & $\begin{array}{c}253 \\
(74.41)\end{array}$ & $\begin{array}{c}72 \\
(21.18)\end{array}$ & $\begin{array}{c}15 \\
(4.41)\end{array}$ \\
\hline $\begin{array}{l}\text { I'm worried that my family might get infected with COVID-19 because of my } \\
\text { dental activities. }\end{array}$ & $\begin{array}{c}318 \\
(93.53)\end{array}$ & $\begin{array}{c}15 \\
(4.41)\end{array}$ & $\begin{array}{c}7 \\
(2.06)\end{array}$ \\
\hline I'm afraid of being quarantined if I get infected with COVID-19. & $\begin{array}{c}272 \\
(80.0)\end{array}$ & $\begin{array}{c}57 \\
(16.76)\end{array}$ & $\begin{array}{c}11 \\
(7.65)\end{array}$ \\
\hline The potential cost of treatment for COVID-19 makes me anxious. & $\begin{array}{c}252 \\
(74.12)\end{array}$ & $\begin{array}{c}75 \\
(22.06)\end{array}$ & $\begin{array}{c}13 \\
(3.82)\end{array}$ \\
\hline I'm afraid to hear that people I may know have died of COVID-19. & $\begin{array}{c}297 \\
(87.35)\end{array}$ & $\begin{array}{c}39 \\
(11.47)\end{array}$ & $\begin{array}{c}4 \\
(1.18)\end{array}$ \\
\hline
\end{tabular}

Post-infection quarantine and treatment costs also resulted in fear and anxiety in $80 \%$ and $74.12 \%$ of the dentists, respectively, whereas hearing about the death of people due to COVID-19 caused fear in $87.35 \%$ of them.

\subsection{Dentists practice towards COVID-19 prevention measures}

Table 6 represents the practice of dentists towards COVID-19 prevention measures. Results showed that $87.72 \%$ of the dentists had good practice toward COVID-19 preventive measures, whereas $7.97 \%$ of them had poor practice. Although dentists' practice did not satisfactorily meet the criteria, such as providing a special disinfectant solution or mask for patients $(12.82 \%)$, disinfecting surfaces every two hours $(12.06 \%)$, regular air conditioning (11.18\%), examining patients' symptoms (10.88\%), and cleaning surfaces in workplaces $(10.29 \%)$, their practice regarding changing gloves after treatment procedures for each patient (97.94\%), changing gloves and washing hands before and after the treatment (95.29\%), and observing hand hygiene before and after changing gloves (95.0\%) was excellent.

\subsection{Correlation coefficients between research variables \\ Correlation coefficients among age, job} experience, and other psychosocial variables are shown in Table 7. Except for the correlation between age and job experience, the strongest correlation coefficients were observed between fear and knowledge $(\mathrm{r}=0.614, \mathrm{P}<0.05)$, as well as practice and knowledge $(\mathrm{r}=0.581, \mathrm{P}<0.05)$, respectively. Moreover, the correlation coefficients between fear and attitude $(\mathrm{r}=0.118, \mathrm{P}<0.05)$, as well as knowledge and age $(\mathrm{r}=0.121, \mathrm{P}<0.05)$ were reported as the weakest ones. All variables showed a positive and significant 


\begin{tabular}{|c|c|c|c|}
\hline Items & $\begin{array}{c}\text { Yes } \\
\mathrm{N}(\%)\end{array}$ & $\begin{array}{c}\text { No } \\
\text { N (\%) }\end{array}$ & $\begin{array}{c}\text { I don't know } \\
\text { N (\%) }\end{array}$ \\
\hline I accurately assess the level of risk and travel history of each patient. & $\begin{array}{c}303 \\
(89.12)\end{array}$ & $\begin{array}{c}16 \\
(4.71)\end{array}$ & $\begin{array}{c}21 \\
(6.18)\end{array}$ \\
\hline $\begin{array}{l}\text { I carefully evaluate the signs of upper respiratory tract infection and patients' body } \\
\text { temperature. }\end{array}$ & $\begin{array}{c}280 \\
(82.35)\end{array}$ & $\begin{array}{c}37 \\
(10.88)\end{array}$ & $\begin{array}{c}23 \\
(6.76)\end{array}$ \\
\hline I clean my hands using soap and water or an alcohol hand rub. & $\begin{array}{c}321 \\
(94.41)\end{array}$ & $\begin{array}{c}13 \\
(3.82)\end{array}$ & $\begin{array}{c}6 \\
(1.76)\end{array}$ \\
\hline I regularly disinfect the environment and surfaces in the workplace. & $\begin{array}{c}274 \\
(80.59)\end{array}$ & $\begin{array}{c}35 \\
(10.29)\end{array}$ & $\begin{array}{c}31 \\
(9.12)\end{array}$ \\
\hline $\begin{array}{l}\text { I always use Personal Protective Equipment, such as gloves, a face shield, and } \\
\text { masks. }\end{array}$ & $\begin{array}{c}312 \\
(91.76)\end{array}$ & $\begin{array}{c}15 \\
(4.41)\end{array}$ & $\begin{array}{c}13 \\
(3.82)\end{array}$ \\
\hline I wash my hands before and after each patient treatment. & $\begin{array}{c}324 \\
(95.29)\end{array}$ & $\begin{array}{c}9 \\
(2.65)\end{array}$ & $\begin{array}{c}7 \\
(2.06)\end{array}$ \\
\hline I change my gloves after the treatment procedure for each patient. & $\begin{array}{c}333 \\
(97.94)\end{array}$ & $\begin{array}{c}7 \\
(2.06)\end{array}$ & $\begin{array}{c}0 \\
(0)\end{array}$ \\
\hline I observe hand hygiene before and after wearing and taking off gloves. & $\begin{array}{c}323 \\
(95.0)\end{array}$ & $\begin{array}{c}8 \\
(2.35)\end{array}$ & $\begin{array}{c}9 \\
(2.65)\end{array}$ \\
\hline $\begin{array}{l}\text { I avoid crowded clinics and make separate appointments with enough time } \\
\text { intervals. }\end{array}$ & $\begin{array}{c}320 \\
(94.12)\end{array}$ & $\begin{array}{c}8 \\
(2.35)\end{array}$ & $\begin{array}{c}12 \\
(3.53)\end{array}$ \\
\hline $\begin{array}{l}\text { I prepare a special alcoholic disinfectant and mask for each patient in the waiting } \\
\text { rooms. }\end{array}$ & $\begin{array}{c}221 \\
(65.0)\end{array}$ & $\begin{array}{c}98 \\
(28.82)\end{array}$ & $\begin{array}{c}21 \\
(6.18)\end{array}$ \\
\hline $\begin{array}{l}\text { I disinfect all surfaces, such as chairs and door handles, every two hours with } \\
\text { chlorine solution and other substances. }\end{array}$ & $\begin{array}{c}277 \\
(81.47)\end{array}$ & $\begin{array}{c}41 \\
(12.06)\end{array}$ & $\begin{array}{c}22 \\
(6.47)\end{array}$ \\
\hline I regularly ventilate the clinic air. & $\begin{array}{c}291 \\
(85.59)\end{array}$ & $\begin{array}{c}38 \\
(11.18)\end{array}$ & $\begin{array}{c}11 \\
(3.24)\end{array}$ \\
\hline
\end{tabular}

Table 7. Correlation coefficients among the variables used in the study ( $\mathrm{n}=340)$

\begin{tabular}{|c|c|c|c|c|c|c|}
\hline Variables & 1 & 2 & 3 & 4 & 5 & 6 \\
\hline 1. Age & 1 & & & & & \\
\hline 2. Job experience & $0.792^{*}$ & 1 & & & & \\
\hline 3. Knowledge & $0.121^{*}$ & $0.242^{* *}$ & 1 & & & \\
\hline 4. Attitude & 0.10 & $0.413^{* *}$ & $0.374^{* *}$ & 1 & & \\
\hline 5. Fear & 0.12 & $0.146^{* *}$ & $0.614^{*}$ & $0.118^{*}$ & 1 & \\
\hline 6. Practice & 0.09 & $0.164^{* *}$ & $0.581^{*}$ & $0.202^{*}$ & $0.482^{* *}$ & 1 \\
\hline
\end{tabular}

relationship with practice towards COVID-19 preventive measures, except for age. Most correlation coefficients were reported at the medium level $(\mathrm{P}<0.05)$.

\subsection{Predictive variables related to COVID-19 preventive measures}

The linear regression analysis using the stepwise method was utilized in order to evaluate the predictive power of the variables based on different studies, as well as appraise the correlation coefficients in the present study (Table 8).

Job experience, knowledge, attitude, and fear were considered variables affecting the preventive practice of COVID-19 in dentists. In the first step, job experience was entered into an equation where the correlation coefficient (R) with dependent variables (preventative practice) was 0.748 . At this stage, the values of $\mathrm{R}^{2}$ and adjusted $\mathrm{R}^{2}$ were 0.560 and 0.555 , respectively. After entering knowledge as the second variable, the value of $R^{2}(0.763)$ and adjusted $R^{2}$ (0.583) increased, subsequently. Similarly, by adding the third variable, attitude, in the third phase, an enhancement was observed in the value of $R(0.780)$ and adjusted $R^{2}$ (0.608). Finally, by adding four variables, such as job experience, knowledge, attitude, and fear in the final model, the values of $\mathrm{R}^{2}$ and adjusted $\mathrm{R}^{2}$ raised to 0.792 and 0.627 , respectively. In other words, regarding the adjusted $\mathrm{R}^{2}$ in the final model, $62.7 \%$ of the variance in the dependent variable (preventive practice) was explained by these four variables. Moreover, based on the $\beta$ coefficients obtained in Table 9 , it can be concluded that job experience, knowledge, attitude, and fear described the highest variance ofpreventive practice in descending order.

\begin{tabular}{|c|c|c|c|c|c|c|}
\hline Variables & $\mathbf{R}$ & $\mathbf{R}^{2}$ & adjusted $\mathbf{R}^{2}$ & std. error of estimate & $\mathbf{F}$ & $\mathbf{P}$ \\
\hline 1. Job experience & 0.748 & 0.560 & 0.556 & 2.44 & 137.254 & $P<0.001$ \\
\hline 2. Knowledge & 0.763 & 0.583 & 0.575 & 2.40 & 74.693 & $\mathrm{P}<0.001$ \\
\hline 3. Attitude & 0.780 & 0.608 & 0.597 & 2.34 & 54.758 & $\mathrm{P}<0.001$ \\
\hline 4. Fear & 0.792 & 0.627 & 0.613 & 2.29 & 44.093 & $\mathrm{P}<0.001$ \\
\hline
\end{tabular}




\begin{tabular}{lccccc}
\hline \multicolumn{2}{l}{ Table 9. Stepwise regression with $\beta$ coefficients, standardized $\beta$ coefficients, T, and P } & & T & P \\
\hline Step & Variables & $\boldsymbol{\beta}$ & Standardized $\boldsymbol{\beta}$ coefficients & 11.716 & 0.000 \\
\hline $\mathbf{1}$ & Job experience & 0.482 & 0.748 & 11.570 & 0.000 \\
$\mathbf{2}$ & Job experience & 0.469 & 0.729 & 2.429 & 0.017 \\
& Knowledge & 0.614 & 0.153 & 10.898 & 0.000 \\
& Job experience & 0.443 & 0.689 & 3.618 & 0.000 \\
$\mathbf{3}$ & Knowledge & 1.306 & 0.325 & 2.607 & 0.010 \\
& Attitude & 0.202 & 0.234 & 6.779 & 0.000 \\
& Job experience & 0.361 & 0.562 & 3.835 & 0.000 \\
$\mathbf{4}$ & Knowledge & 1.364 & 0.340 & 2.632 & 0.010 \\
& Attitude & 0.200 & 0.231 & 2.313 & 0.023 \\
\hline
\end{tabular}

\section{Discussion}

This study was conducted from April to July 2020 in the middle of the COVID-19 pandemic. It should be noted that the prevalence of COVID-19 in Iran was far higher than expected due to the government's inappropriate actions as well as people's noncompliance with health protocols. Therefore, the current study aimed to determine the status of knowledge, attitude, and fear in dentists, in addition to appraising the effect of these variables on their preventative practice towards COVID-19.

Although Iran had made great strides between April and June 2020 in controlling and preventing the death of patients, compared to some developed countries, there were still several problems in managing the epidemic. Insufficient information and lack of awareness, along with disbelief in vulnerability, led to an acceleration of the disease outbreak in some provinces, such as Tehran and other Northern provinces, Iran. In addition to psychosocial factors, numerous holidays resulted in an increase in trips to Northern provinces, such as Mazandaran, Gilan, Golestan, and Qazvin with respect to tourist attractions, which subsequently elevated the prevalence (34).

In the present study, $73.53 \%$ of the dentists had good knowledge about COVID-19; however, their mean knowledge scores on topics, such as incubation period (18.82\%), laboratory testing $(20.0 \%)$, the duration of lasting the virus on surfaces (12.94\%), and methods of disinfection of surfaces $(11.47 \%)$ were weak. Our findings on the dentists' high level of knowledge about COVID-19 were in line with the results of studies conducted in Italy, Brazil, and Lebanon, as well as the findings of a study performed by Kamate et al. (2020) who found that the majority of dentists, being from several countries, had an appropriate level of knowledge in this issue $(26,30,35,36)$.

Moreover, according to the current study, $74.8 \%$ of the dentists had not formally contributed to any training program on the prevention of COVID-19, whereas given the results of a study conducted by Arora et al. (2020), not only $60.7 \%$ of the dentists were formally trained in infection control but also $49.7 \%$ of them received specific training for COVID19 prevention protocols (37). Additionally, 30\% of the dentists participating in the study reported the educational resources of the Ministry of Health, WHO, and CDC as the main reference of information, and consequently, the mean score of knowledge in this group of dentists was significantly higher than the others $(\mathrm{P}<0.001)$.

As demonstrated by Saqlain et al. (2020), the mean score of knowledge in HCWs, mostly using social media as the main source of information about COVID19 prevention, was significantly lower than others (38). Therefore, the lack of application of valid educational resources (WHO, CDC, and Ministry of Health) may be considered one of the reasons for the dentists' lower mean score of knowledge in the study. Bhagavathula et al. (2020) emphasized that HCWs would better apply reliable sources to seek information on COVID-19, such as guidelines published by WHO and CDC (18). The absence of monitoring of the health content of social media, such as Instagram and public websites, could remarkably lessen the scientific credibility of this resource. As a result, a pandemic of misinformation would strongly influence the decision of HCWs to prevent COVID-19 (39).

Considering the optimal attitude and effective performance of HCWs, such as dentists depend on their level of knowledge about COVID-19, an increase in their knowledge concerning coronavirus is an undeniable necessity. In addition, updating the scientific content of websites relevant to the Ministry of Health and related institutions and focusing on the prevention of COVID-19 in dentists, can play an important role in enhancing the level of knowledge in dentists and preventing their misinformation.

Our results also showed that almost $79.42 \%$ of the dentists did not have the desired attitude toward implementing more protocols to prevent COVID-19 and believed that following routine protocols were sufficient for it. This is while during the COVID-19 pandemic, dentists must consider themselves vulnerable to COVID-19, with having a proper comprehension of the risk of disease. Dentists should also be aware that coronavirus can last on surfaces for hours or more depending on the type of surface, temperature, and humidity (40).

Therefore, performing routine protocols may not be adequate to manage the risk of transmission of infection. According to this study, $48.82 \%$ of the dentists believed that they were likely to get infected 
with COVID-19 similar to other HCWs. It has been reported that the proximity between patients and dentists (approximately 35-40 cm), as well as some time-consuming special treatment procedures could put dentists at a greater danger of infection with COVID-19, compared to other HCWs (41). Moreover, nearly one-third of participants believed that with a strong immune system, they would no longer be infected with COVID-19, with more than 45\% believing that the possibility of infection transmission through their patients will be too low since they are responsible people. Overall, $59.96 \%$ of the dentists had a very unfavorable attitude, with $30.44 \%$ having a desirable attitude.

Dentists are encouraged to follow health protocols when their colleagues and other HCWs carefully follow preventive protocols (17). In other words, high perceived vulnerability along with a high level of knowledge had a positive relationship with attitude towards COVID-19 preventive measures. Even dentists' knowledge of the number of HCWs infected with COVID-19 is likely to increase their perceived vulnerability to the disease. On the other hand, dentists without enough knowledge on COVID19 would have an optimistic attitude about rapid recovery after it similar to other infectious diseases. If dentists accept that they are vulnerable to COVID19 , they will probably engage in preventative behaviors. In this regard, Taghrir et al. (2020) have highlighted the significant relationship between risk perception and adherence to preventative behaviors (42). Therefore, optimistic assessments of the likelihood of infecting and misunderstanding of the consequences of a threat could be considered obstacles to the full implementation of COVID-19related hygiene protocols. Accordingly, reflecting the experience of other dentists accompanied by providing real statistics on the number of HCWs infected with COVID-19 and focus group discussions through video conferencing can be good strategies to change dentists' attitudes about the importance of adhering to COVID-19-related hygiene protocols.

The mean score of attitude had a significant correlation with the mean score of knowledge $(\mathrm{P}<0.01, \mathrm{r}=0.368)$, which was in parallel with the results of a study conducted by Abdel Wahed et al. (2020) (43). The link between HCWs' level of knowledge and their attitudes toward COVID-19 preventive measures has been reported in previous studies $(14,42,44)$. The knowledge of HCWs is a momentous prerequisite for positive attitudes, prevention beliefs, as well as promoting preventive practice, with some effects on coping strategies (45). Simultaneously, inadequate knowledge alongside factors, such as the type and frequency of exposure, could intensify the risk of infection (46). Despite the high level of knowledge of dentists, our results revealed that they do not have a favorable attitude towards COVID-19 preventative measures, at least in some cases, such as the responsibility of patients and their own vulnerability. In the present study, approximately, $33 \%$ of the dentists believed that they were more susceptible to COVID-19 than any other HCWs, contradicting the findings of previous research, in which roughly, $83 \%$ of the participants considered themselves vulnerable to COVID-19 (14, 46). The amount of perceived risk can strongly affect both the preparedness to react to risk and the mental health of individuals to exposure dangers (47). Accordingly, determining the perceived risks in dentists can be regarded as a crucial tool to alter attitudes and make their workplace safer.

Regarding another important finding of this study, $83.21 \%$ of the dentists declared that they would be severely blamed by the community if they got infected with COVID-19. The rates of blame in the studies conducted by Wahed et al. (2020) and Abdelhafiz et al. (2020) were reported to be $66 \%$ and $23 \%$, respectively $(43,48)$. Fear about the high mortality of a disease and the possibility of transmitting its infection to family members are considered the main determinants of stigma (45).

In addition, parts of the stigma may be due to the legal restrictions on conducting religious funeral services. On the other hand, by getting HCWs infected with COVID-19, the majority of society would become frustrated at its prevention, and as a result, the disease will outspread. In this regard, proper training and the implementation of stigma reduction programs accompanied by the announcement of health care policies could be employed as approaches to counteracting stigma (49).

This study also identified that the majority of dentists $(82.11 \%)$ had fear and anxiety towards various issues listed in the fear scale. This was consistent with the results of a study performed by Ahmed et al. (2020) who reported that most dentists were afraid of issues as being infected by patients or colleagues and providing treatment to suspected patients (20). Aly and Elchaghaby (2020) also highlighted $90 \%$ fear of similar issues in dental professionals (50). Dentists' knowledge of incubation periods accompanied by the unique features of dental processes (e.g., proximity to patients) can intensify their fear and anxiety, as well as predicting a significant correlation between knowledge and fear of COVID-19.

In line with the results of previous studies, infection with COVID-19 through patients or colleagues, treatment of suspected patients, nonobservance of social distance with patients, the possibility of transmitting the infection to family members, post-infection quarantine, and treatment costs due to COVID-19, as well as news related to mortality were the main causes of dentists' fear and anxiety in this study $(20,51)$.

One of the factors influencing fears was the perceived risk of transmitting the infection to the 
family members (93.5\%), which was in accordance with the study of De Leo et al. (2020) (52). Previous studies have displayed that HCWs having children, the elderly, or the sick at home show higher levels of fear $(16,51,52)$. Moreover, according to studies, extra risks and exposure can be diminished by taking appropriate precautions at home, such as washing hands, changing work clothes and bathing, keeping a reasonable social distance, especially with children and the elderly, avoiding sharing dishes, and using a separate plate/glass/bowl (16).

Although HCWs are at a higher risk of infecting with COVID-19, compared to non-HCWs, even so, the majority of them (97\%) will not get infected (53). Furthermore, even though providing care to patients with COVID-19 makes HCWs more at risk, the effective application of PPE reduces the risk of infection to a minimum (54). Lai et al. (2020) reported that even in front-line health workers working in high-risk areas, the incidence of COVID-19 was only $0.55 \%$ (55). Moreover, the risk of HCWs becoming infected with COVID-19 was $0.14 \%$ in comparison with $0.10 \%$ in the general population (56).

Exposure to dramatic images of malignant patients and high mortality rates from social media can lead to overestimation of the personal risk of infection by HCWs and dentists (57). Therefore, there is no sensible basis for dentists' fear of transmitting the infection to the family. In this regard, the provision of PPE and increased preventative practice along with supplying real statistics on the number of HCWs infected with COVID-19 through changing dentists' attitudes could remarkably lessen dentists' anxiety and fear.

The total score of practice towards COVID-19 preventative measures in dentists was relatively high, and $87.72 \%$ of them had an optimal performance. However, they did not meet all the criteria, which was in agreement with the findings of previous studies $(30,36,38)$. It was also identified that their practice towards COVID-19 preventative measures was significantly associated with job experience, knowledge, attitude, and fear $(\mathrm{P}<0.05)$. Nonetheless, weakness in some preventive measures could accelerate the spread of the virus in the community. It is recommended that the Ministry of Health provides appropriate preventive protocols to all dentists during the COVID-19 pandemic and get ensured that these protocols comply with all the items relevant to preventative measures.

Regression analysis showed that job experience, knowledge, attitude, and fear were significant predictors of dentists' practice towards COVID-19 preventive measures, and $62.7 \%$ of the variance of preventive practice could be explained by these variables, which was consistent with the findings of previous studies $(20,27,38)$. The association among these variables and preventive practice clearly emphasizes the importance of improving dentists' knowledge through health education, which may lead to an improvement in their attitude and practice towards COVID-19. Additionally, weaknesses in some practice items may be due to a lack of adequate training. Online training courses should be considered an accessible and effective strategy to increase dentists' adherence to infection control guidelines.

\section{Conclusion}

The findings of the present study demonstrated that dentists had a relatively good level of knowledge, attitude, and practice towards COVID-19 preventive measures. The pandemic of COVID-19 has had a significant impact on the dental profession, causing the majority of dentists to overestimate their risk of getting infected with COVID-19 due to high fear and anxiety.

\section{Limitations}

Despite the impressive results, it should be emphasized that our study faced some limitations. First, the dentists participating in this study were selected from five Northern provinces of Iran, which cannot represent the entire dental community. Therefore, the selection of larger samples from all geographical areas of Iran will strengthen the generalizability of the results. Second, the utilization of a self-report method to collect data may be biased. Therefore, the possibility of recording some variables, such as preventive behaviors via observation or reporting by colleagues can decline bias to some extent. Third, given the feasibility of transmitting the disease through physical contact, using online methods can be useful tools for collecting data quickly, safely, and cost-effectively. Finally, concerning the cross-sectional nature of the present study, it would only show associations and not be able to provide cause-effect relationships.

\section{Recommendation}

Our findings would have important implications for the development of strategies for reducing dentists' anxiety and fear via changing attitudes, which could be achieved through providing adequate PPE and subsequently enhancing preventive practice, raising awareness via online training regarding new guidelines (e.g., WHO or CDC), and presenting realtime statistics on the number of HCWS infected with COVID-19.

\section{Acknowledgments}

The authors would like to appreciate the cooperation of all dentists of Tehran, Qazvin, Gilan, Mazandaran, and Golestan Universities of Medical Sciences in this study. The authors are also grateful to all dentists who contributed to this investigation. 


\section{Footnotes}

Authors' Contribution: Study concept and design: Isa Mohammadi Zeidi; acquisition of data, analysis, and interpretation: Banafsheh Mohammadi Zeidi. Conflicts of Interest: The authors have no conflict of interest to declare.

Ethical Approval: This study was approved by the Ethics Committee of Qazvin University of Medical Sciences (Ethical code: IR.QUMS.REC.1399.190)

Funding/Support: This research was funded by the Research and Technology Deputy of Qazvin University of Medical Sciences, Iran.

Financial Disclosure: None

Informed consent: Informed consent was obtained from all participants at the start of the study.

\section{References}

1. Gralinski LE, Menachery VD. Return of the coronavirus: 2019nCoV. Viruses. 2020;12(2):135. doi: 10.3390/v12020135. [PubMed: 31991541].

2. Neher RA, Dyrdak R, Druelle V, Hodcroft EB, Albert J. Potential impact of seasonal forcing on a SARS-CoV-2 pandemic. Swiss Med Wkly. 2020;150:w20224. doi: 10.4414/smw.2020.20224. [PubMed: 32176808].

3. Peng $\mathrm{X}, \mathrm{Xu} \mathrm{X}, \mathrm{Li} \mathrm{Y}$, Cheng L, Zhou X, Ren B. Transmission routes of 2019-nCoV and controls in dental practice. Int J Oral Sci. 2020;12(1):1-6. doi: 10.1038/s41368-020-0075-9. [PubMed: 32127517].

4. Fu L, Wang B, Yuan T, Chen X, Ao Y, Fitzpatrick T, et al. Clinical characteristics of coronavirus disease 2019 (COVID-19) in China: a systematic review and meta-analysis. J Infect. 2020;80(6):656-65. doi: 10.1056/NEJMoa2002032. [PubMed: 32109013].

5. Zhang L, Liu Y. Potential interventions for novel coronavirus in China: a systematic review. J Med Virol. 2020;92(5):479-90. doi: 10.1002/jmv.25707. [PubMed: 32052466].

6. Wu P, Hao X, Lau EHY, Wong JY, Leung K, Wu JT, et al. Real-time tentative assessment of the epidemiological characteristics of novel coronavirus infections in Wuhan, China, as at 22 January 2020. Eur Surveill. 2020;25(3):2000044. doi: 10.2807/15607917.ES.2020.25.3.2000044. [PubMed: 31992388].

7. Schwartz J, King CC, Yen MY. Protecting health care workers during the COVID-19 coronavirus outbreak -Lessons from Taiwan's SARS response. Clin Infect Dis. 2020;71(15):858-60. doi: 10.1093/cid/ciaa255. [PubMed: 32166318].

8. Meng L, Hua F, Bian Z. Coronavirus disease 2019 (COVID-19): emerging and future challenges for dental and oral medicine. $J$ Dent Res. 2020;99(5):481-7. doi: 10.1177/0022034520914246. [PubMed: 32162995].

9. Barbieri T, Basso G, Scicchitano S. Italian workers at risk during the Covid-19 epidemic. Italian Econ J. 2021;23:1-21. doi: 10.1007/s40797-021-00164-1.

10. Peditto M, Scapellato S, Marcianò A, Costa P, Oteri G. Dentistry during the COVID-19 epidemic: an Italian workflow for the management of dental practice. Int J Environ Res Public Health. 2020;17(9):3325. doi: 10.3390/ijerph17093325. [PubMed: 32403248].

11. Sarkarat F, Tootoonchian A, Haraji A, Rastegarmoghaddam M, Mostafavi SM, Naghibi S. Evaluation of dentistry staff involvement with COVID-19 in the first 3 month of epidemiologic spreading in Iran. J Res Dent Sci. 2020; 17(2):137-45. doi: 10.29252/jrds.17.2.137.

12. Krithikadatta J, Nawal RR, Amalavathy K, McLean V, Gopikrishna A. Endodontic and dental practice during COVID19 pandemic: position statement from the Indian Endodontic Society, Indian Dental Association, and International
Federation of Endodontic Associations. Endodontology. 2020; 32(2):55-66

13. Occupational Safety and Health Administration. Guidance on preparing workplaces for COVID-19. Washington, D.C: Occupational Safety and health Administration; 2020.

14. Mceachan R, Hons BA, Taylor N, Lawton R, Gardner P, Conner M. Meta-analysis of the reasoned action approach (RAA) to understanding health behaviors. Ann Behav Med. 2016; 50(4):592-612. doi: 10.1007/s12160-016-9798-4. [PubMed: 27169555].

15. Geldsetzer P. Use of rapid online surveys to assess people's perceptions during infectious disease outbreaks: a crosssectional survey on COVID-19. J Med Internet Res. 2020; 22(4):e18790. doi: 10.2196/18790. [PubMed: 32240094].

16. Ge Z, Yang L, Xia J, Fu XH, Zhang YZ. Possible aerosol transmission of COVID-19 and special precautions in dentistry. J Zhejiang Univ Sci. 2020;21(5):361-8. doi: 10.1631/jzus.B2010010. [PubMed: 32425001].

17. Gan WH, Lim JW, Koh D. Preventing intra-hospital infection and transmission of coronavirus disease 2019 in health-care workers. Saf Health Work. 2020;11(2):241-43. doi: 10.1016/j.shaw.2020.03.001. [PubMed: 32292622].

18. Bhagavathula AS, Aldhaleei WA, Rahmani J, Mahabadi MA, Bandari DK. Knowledge and perceptions of COVID-19 among health care workers: cross-sectional study. JMIR Public Health Surveill. 2020;6(2):e19160. doi: 10.2196/19160. [PubMed: 32320381].

19. Guo H, Zhou Y, Liu X, Tan J. The impact of the COVID-19 epidemic on the utilization of emergency dental services. $J$ Dent Sci. 2020;15(4):564-7. doi: 10.1016/j.jds.2020.02.002. [PubMed: 32296495].

20. Ahmed MA, Jouhar R, Ahmed N, Adnan S, Aftab M, Zafar MS, et al. Fear and practice modifications among dentists to combat novel coronavirus disease (COVID-19) outbreak. Int J Environ Res Public Health. 2020;17(8):2821. doi: 10.3390/ijerph17082821. [PubMed: 32325888].

21. Shacham M, Hamama-Raz Y, Kolerman R, Mijiritsky O, Ben-Ezra M, Mijiritsky E. COVID-19 factors and psychological factors associated with elevated psychological distress among dentists and dental hygienists in Israel. Int J Environ Res Public Health. 2020;17(8):2900. doi: 10.3390/ijerph17082900. [PubMed: 32331401].

22. Harper CA, Satchell LP, Fido D, Latzman RD. Functional fear predicts public health compliance in the COVID-19 pandemic. Int J Ment Health Addict. 2020;27:1-14. doi: 10.1007/s11469020-00281-5. [PubMed: 32346359].

23. Wang C, Pan R, Wan X, Tan Y, Xu L, Ho CS, et al. Immediate psychological responses and associated factors during the initial stage of the 2019 coronavirus disease (COVID-19) epidemic among the general population in China. Int J Environ Res Public Health. 2020;17:1729. doi: 10.3390/ijerph17051729. [PubMed: 32155789].

24. Ren SY, Gao RD, Chen YL. Fear can be more harmful than the severe acute respiratory syndrome coronavirus 2 in controlling the corona virus disease 2019 epidemic. World $J$ Clin Cases. 2020;8(4):652-7. doi: 10.12998/wjcc.v8.i4.652. [PubMed: 32149049].

25. Consolo U, Bellini P, Bencivenni D, Iani C, Checchi V. Epidemiological aspects and psychological reactions to COVID19 of dental practitioners in the northern italy districts of Modena and Reggio Emilia. Int J Environ Res Public Health. 2020;17(10):3459. doi: 10.3390/ijerph17103459. [PubMed: 32429193].

26. Putrino A, Raso M, Magazzino C, Galluccio G. Coronavirus (COVID-19) in Italy: knowledge, management of patients and clinical experience of Italian dentists during the spread of contagion. BMC Oral Health. 2020;20(1):200. doi: 10.1186/s12903-020-01187-3. [PubMed: 32650753].

27. Gambhir SR, Dhaliwal SJ, Aggarwal A, Anand S, Anand V, Kaur Bhangu A. Covid-19: a survey on knowledge, awareness and hygiene practices among dental health professionals in an Indian scenario. Rocz Panstwow Zakl Hig. 2020;71(2):223-9. doi: 10.32394/rpzh.2020.0115. [PubMed: 32519827].

28. Michie S, van Stralen MM, West R. The behavior change wheel: a 
new method for characterizing and designing behavior change interventions. Implement Sci. 2011;6:42. doi: 10.1186/17485908-6-42. [PubMed: 21513547].

29. Araújo-Soares V, Hankonen, N, Justin P, Rodrigues A, Sniehotta FF. Developing behavior change interventions for selfmanagement in chronic illness. Eur Psychol. 2018;24(1):7-25. doi: 10.1027/1016-9040/a000330. [PubMed: 31496632].

30. Kamate SK, Sharma S, Thakar S, Srivastava D, Sengupta K, Hadi AJ, et al. Assessing knowledge, attitudes and practices of dental practitioners regarding the COVID-19 pandemic: a multinational study. Dent Med Probl. 2020;57(1):11-7. doi: 10.17219/dmp/119743. [PubMed: 32307930].

31. Khader Y, Al Nsour M, Al-Batayneh OB. Dentists' awareness, perception, and attitude regarding COVID-19 and infection control: cross-sectional study among Jordanian dentists. JMIR Public Health Surveill. 2020;6(2):e18798. doi: 10.2196/18798. [PubMed: 32250959].

32. Prasetyo Y, Castillo AM, Salonga LJ, Sia JA, Seneta JA. Factors affecting perceived effectiveness of COVID-19 prevention measures among Filipino during enhanced community quarantine in Luzon, Philippines: integrating protection motivation theory and extended theory of planned behavior. Int $J$ Infect Dis. 2020;99:312-23. doi: 10.1016/j.ijid.2020.07.074. [PubMed: 32768695].

33. Bakaeen LG, Masri R, AlTarawneh S, Garcia LT, AlHadidi A, Khamis $\mathrm{AH}$, et al. Dentists knowledge, attitudes and professional behavior towards COVID-19 pandemic: a multi-site survey of dentists' perspectives. J Am Dent Assoc. 2021;152(1):16-24. doi: 10.1016/j.adaj.2020.09.022. [PubMed: 33250171].

34. Mohammadzadeh N, Shahriary M, Shirmohammadlou N, Lohrasbi V. A glance at the prevalence of coronavirus disease 19 (COVID19) in Iran: strengths and weaknesses. Inf Control Hosp Epidemiol. 2020;41(12):1479-82. doi: 10.1017/ice.2020.193. [PubMed: 32362292].

35. Sezgin GP, ŞirinoĞlu Çapan B. Assessment of dentists' awareness and knowledge levels on the Novel Coronavirus (COVID-19). Braz J Oral Res. 2020;34:e112. doi: 10.1590/1807-3107bor2020.vol34.0112. [PubMed: 32876114].

36. Nasser Z, Fares Y, Daoud R, Abou-Abbas L. Assessment of knowledge and practice of dentists towards coronavirus disease (COVID-19): a cross-sectional survey from Lebanon. BMC Oral Health. 2020;20(1):281. doi: 10.1186/s12903-02001273-6. [PubMed: 33050914].

37. Arora S, Abullais Saquib S, Attar N, Pimpale S, Saifullah Zafar K, Saluja $P$, et al. Evaluation of knowledge and preparedness among indian dentists during the current COVID-19 pandemic: a cross-sectional study. J Multidiscip Healthc. 2020;13:841-54. doi: 10.2147/JMDH.S268891. [PubMed: 32922024].

38. Saqlain M, Munir MM, Ur Rehman S, Gulzar A, Naz S, Ahmed Z. Knowledge, attitude, practice and perceived barriers among health- care professionals regarding COVID-19: a crosssectional survey from Pakistan. J Hosp Infect. 2020;105(3): 419-23. doi: 10.1016/j.jhin.2020.05.007. [PubMed: 32437822].

39. Huynh G, Nguyen TN, Vo KN, Pham LA. Knowledge and attitude toward COVID-19 among healthcare workers at District 2 Hospital, Ho Chi Minh City. Asian Pac J Trop Med. 2020;13(6):260. doi: 10.4103/1995-7645.280396.

40. Pîrvu C, Pătraşcu I, Pîrvu D, Ionescu C. The dentist's operating posture - ergonomic aspects. J Med Life. 2014;7(2):177-82. [PubMed: 25184007].

41. Fusco FM, Pisaturo M, Iodice V, Bellopede R, Tambaro O, Parrella G, et al. COVID-19 among healthcare workers in a specialist infectious diseases setting in Naples, Southern Italy: results of a cross-sectional surveillance study. J Hosp Infect. 2020;105(4):596-600. doi: 10.1016/j.jhin.2020.06.021. PubMeD: 32565367].

42. Taghrir MH, Borazjani R, Shiraly R. COVID-19 and Iranian medical students; a survey on their related-knowledge, preventive behaviors and risk perception. Arch Iran Med.
2020;23(4):249-54. doi: 10.34172/aim.2020.06. [PubMed: 32271598].

43. Abdel Wahed WY, Hefzy EM, Ahmed MI. Assessment of knowledge, attitudes, and perception of health care workers regarding COVID-19, a cross-sectional study from Egypt. I Community Health. 2020;45(6):1242-51. doi: 10.1007/s10900-020-00882-0. [PubMed: 32638199].

44.Zhang M, Zhou M, Tang F, Wang Y, Nie H, Zhang L, et al. Knowledge, attitude, and practice regarding COVID-19 among healthcare workers in Henan, China. J Hosp Infect. 2020; 105(2):183-7. doi: 10.1016/j.jhin.2020.04.012. [PubMed: $32278701]$.

45. Jiang l, Ng IHL, Hou Y, Li D, Tan L, Ho H, et al. Infectious disease transmission: survey of contacts between hospital-based healthcare workers and working adults from the general population. J Hosp Infect. 2018;98(4):404-11. doi: 10.1016/ j.jhin.2017.10.020. [PubMed: 29097147].

46. Maleki S, Najafi F, Farhadi K, Fakhri M, Hosseini F. Knowledge, attitude and behavior of health care workers in the prevention of COVID-19. BMG Med Educ. 2020;3:1-17. doi: 10.21203/rs.3.rs23113/v1.

47. Yesilgul G, Cicek H, Avci M, Huseyniklioglu B. Nurses' knowledge levels and perceptions regarding occupational risks and hazards. Int J Caring Sci. 2018;11(2):1117-24.

48. Abdelhafiz AS, Mohammed Z, Ibrahim ME. Knowledge, perceptions, and attitude of Egyptians towards the novel coronavirus disease (COVID-19). J Community Health. 2020; 45(5):881-90. doi: 10.1007/s10900-020-00827-7. [PubMed: 32318986].

49. Kabbash IA, Abo Ali EA, Elgendy MM, Abdrabo MM, Salem HM, Gouda MR, et al. HIV/AIDS-related stigma and discrimination among health care workers at Tanta University Hospitals Egypt. Environ Sci Pollut Res Int. 2018;25(31):30755-62. doi: 10.1007/s11356-016-7848-x. [PubMed: 27752955].

50. Aly MM, Elchaghaby MA. Impact of novel coronavirus disease (COVID-19) on Egyptian dentists' fear and dental practice (a cross-sectional survey). BDJ Open. 2020;6:19. doi: 10.1038/s41405-020-00047-0. [PubMed: 33072400].

51. Kumar J, Katto MS, Siddiqui AA, Sahito B, Ahmed B, Jamil M, et al. Predictive factors associated with fear faced by healthcare workers during COVID-19 pandemic: a questionnaire-based study. Cureus. 2020;12(8):e9741. doi: 10.7759/cureus.9741. [PubMed: 32944456].

52. de Leo D, Trabucchi M. COVID-19 and the fears of Italian senior citizens. Int J Environ Res Public Health. 2020;17(10):3572. doi: 10.3390/ijerph17103572. [PubMed: 32443683].

53. COVID-19 Scientific Advisory Group. COVID-19 Scientific advisory group rapid response report. Edmonton, AB: Alberta Health Services; 2020.

54. Liu M, Cheng S, Xu K, Yang Y, Zhu, QT, Zhang H, et al. Use of personal protective equipment against coronavirus disease 2019 by healthcare professionals in Wuhan, China: Cross sectional study. BMJ. 2020;369:m2195. doi: 10.1136/bmj.m2195. [PubMed: 32522737].

55. Lai J, Ma S, Wang Y, Cai Z, Hu J, Wei N, et al. Factors associated with mental health outcomes among health care workers exposed to coronavirus disease 2019. JAMA Netw Open. 2020;3(3): e203976. doi: 10.1001/jamanetworkopen.2020.3976. [PubMed: 32202646].

56. Kluytmans-van den BF, Buiting AG, Pas SD, Bentvelsen RG, van den Bijllaardt W, van Oudheusden A, et al. Prevalence and clinical presentation of health care workers with symptoms of coronavirus disease 2019 in 2 Dutch hospitals during an early phase of the pandemic. JAMA Netw Open. 2020;3(5):e209673. doi: 10.1001/jamanetworkopen.2020.9673. [PubMed: 32437576].

57. Taylor S. The psychology of pandemics: preparing for the next global outbreak of infectious disease. Newcastle upon Tyne: Cambridge Scholars Publishing; 2020. 